\title{
Mean Platelet Volume in Myocardial and Neurological Injury Associated with Carbon Monoxide Poisoning
}

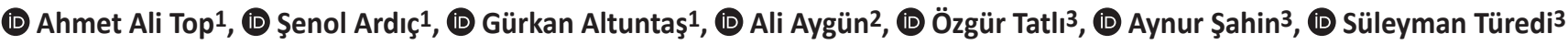 \\ ${ }^{1}$ Kanuni Training and Research Hospital, Clinic of Emergency Medicine, Trabzon, Turkey \\ 2Ordu University Faculty of Medicine, Department of Emergency Medicine, Ordu, Turkey \\ ${ }^{3}$ Karadeniz Technical University Faculty of Medicine, Department of Emergency Medicine, Trabzon, Turkey
}

\section{Abstract}

Objective: Carbon monoxide (CO) poisoning is one of the most commonly encountered causes of fatal intoxication worldwide. Mean platelet volume (MPV) elevation has been shown in several diseases associated with tissue hypoxia and inflammation. This study investigated the association between MPV levels and CO poisoning and examined the relations between MPV and myocardial or neurological injury.

Methods: The research was planned as a single-center, prospective, cross-sectional clinical study. Cases with ischemic chest pain, ischemic electrocardiography change, or troponin elevation were classified as CO poisoning-related myocardial injury. Cases with severe neurological findings were classified as CO poisoning-related neurological injury.

Results: Eighty-nine patients with CO poisoning and 20 healthy volunteers were enrolled. Mean MPV levels at the presentation in patients with CO poisoning were $9.26 \pm 0.99$ femtolitre $(\mathrm{fL})$, and $9.19 \pm 0.97(\mathrm{fL})$ in patients with myocardial injury and $9.11 \pm 1.04(\mathrm{fL})$ in those with neurological injury. MPV values at the presentation in patients with CO poisoning were significantly higher than those in healthy volunteers $(p<0.001)$.

Conclusion: MPV rises significantly in CO poisoning compared to healthy individuals. However, this is not correlated with the clinical findings that may emerge and does not appear to be a reliable parameter in identifying the potential myocardial or neurological injury.

Keywords: Carbon monoxide poisoning, mean platelet volume, hypoxia, platelet activation

\section{INTRODUCTION}

Carbon monoxide (CO) is a colorless, tasteless, scentless, and non-irritating gas resulting from the incomplete burning of carbon-containing fuels $(1,2)$. CO poisoning is one of the most commonly encountered causes of fatal intoxication worldwide. Various clinical outcomes, including such nonspecific symptoms as coma, may occur depending on the degree of poisoning. The early and late injury occurs in several organs, including the brain, heart, skeletal muscle, and kidneys. The most commonly affected systems in CO poisoning are the central nervous system and cardiovascular system, with their high oxygen dependence. Mortality, to a large extent, results from the involvement of these two systems, the most sensitive to the toxic effects of $\mathrm{CO}(3,4)$. The most important cause of the development of toxic effects in CO poisoning is tissue hypoxia, which results from the binding affinity to the hemoglobin of $\mathrm{CO}$ being higher than that of oxygen (5-7). CO, as in anemia, triggers myocardial damage by reducing oxygen content in the blood presented in the myocardium (8). Also, CO causes direct cellular injury by combining with extravascular proteins and also leads to the formation of free oxygen radicals by affecting oxidative metabolism. Inflammation and oxidation accompanying hypoxia in CO poisoning also contribute to the emergence of toxic effects $(9,10)$.

Phone: +90 5052681711 E-mail: dr_aliaygun@hotmail.com ORCID ID: orcid.org/0000-0002-5190-1445

Cite this article as: Top AA, Ardıç \$, Altuntaș G, Aygün A, Tatlı Ö, Şahin A, Türedi S. Mean Platelet Volume in Myocardial and Neurological Injury Associated with Carbon Monoxide Poisoning. Eur Arch Med Res 2020; 36 (1):17-24

๑Copyright 2020 by the University of Health Sciences Turkey, Okmeydanı Training and Research Hospital

European Archives of Medical Research published by Galenos Publishing House. 
While platelets are primarily involved in preventing bleeding, they may also be involved in the release of pro-inflammatory, antiinflammatory, and angiogenic factors, and in the accumulation of leukocytes and progenitor cells in areas of vascular injury and inflammation (11). Karabacak et al. (12) postulated the involvement of platelet activation in the etiopathogenesis of acute CO poisoning and investigated mean platelet volume (MPV), a marker of platelet activation, in patients presenting with CO intoxication. They determined higher levels than in the control group (12). MPV is one of the parameters routinely tested at complete blood count, and is a widely used indicator of platelet function, showing the mean volume of platelets in the circulation. Increased platelet activation and MPV elevation have been shown in several diseases associated with tissue hypoxia and inflammation $(13,14)$.

This study was planned around the hypothesis of a possible association between MPV levels and clinical symptoms. The purpose of the study was to examine the relation between MPV levels and the development of myocardial or neurological injury.

\section{METHODS}

\section{Design and Setting}

The research was planned as a single-center, prospective, crosssectional clinical study. It was performed in the emergency department of a tertiary hospital receiving 200.000 patient presentations annually. Patients presenting to the emergency department due to CO poisoning in the six months following receipt of approval from Kanuni Training and Research Hospital ethical committee (no: 2014/13) were enrolled as the study group. Information concerning the study was given to and signed consent received from all patients volunteering to participate, or from relatives if patients were unable to express consent. Also, 20 healthy volunteers were enrolled in order to determine any variation in MPV between patients with $\mathrm{CO}$ poisoning and healthy individuals.

\section{Study Population}

All patients with suspected CO poisoning based on their histories and physical examination, with serum carboxyhemoglobin $(\mathrm{COHb})$ levels at the time of presentation above threshold values (>5\% for smokers and $>2 \%$ for non-smokers) and aged over 18 were enrolled as the study group. Patients not meeting these criteria or not being monitored due to needing to be transferred to another center for any reason were excluded from the study.
Clinical and demographic characteristics such as age at the time of presentation, sex, symptoms, physical examination findings, Glasgow Coma scale, electrocardiography (ECG), and laboratory records were recorded. Significant clinical parameters, such as symptoms, findings, and treatment administered throughout the study from the time of presentation, were also recorded. Patients with any one of ischemic chest pain, ischemic ECG changes, or troponin elevation at the end of the study period were classified as the CO poisoning-related myocardial injury group. Differences in terms of $\mathrm{COHb}$ and MPV between patients with or without myocardial injury were investigated. Patients with CO poisoning with more serious neurological symptoms and findings, other than mild headache and dizziness, such as lethargy, loss of consciousness, seizure, or coma, were classified as subjects with CO poisoning-related neurological injury. Differences in terms of $\mathrm{COHb}$ and MPV between patients with or without neurological injury were investigated.

MPV levels were also measured, after receipt of consent, from 20 healthy volunteers presenting to the emergency department in order to compare MPV between patients with $\mathrm{CO}$ poisoning and healthy individuals.

\section{Laboratory Measurements}

Patients' $\mathrm{COHb}$ and MPV levels were measured twice, at presentation to the emergency department, and at discharge after hyperbaric oxygen (HBO) or normobaric oxygen (NBO) therapy. Only one blood specimen was taken from the healthy control for MPV measurement. Blood specimens collected for MPV measurements were placed into ethylenediaminetetraacetic acid containing tubes. Measurements were performed within $15 \mathrm{~min}$ using a Mindray BC-5800 automatic hematology analyzer. $\mathrm{COHb}$ measurement was performed from arterial blood specimens using a radiometer Abl80 CO-OX blood gas analysis device.

\section{Statistical Analysis}

Collected data were entered into SPSS 13. software for statistical analysis. Compatibility with the normal distribution of numerical data was evaluated using the Kolmogorov-Smirnov test. Categoric data were expressed as frequency and percentage $(\mathrm{n}, \%)$ and numerical data as mean \pm standard deviation. The Student's t-test was used to compare normally distributed numerical data in independent groups and the chi-square test for the comparison of categoric data. Wilcoxon's t-test was used to compare $\mathrm{COHb}$ and MPV levels at the time of presentation to the emergency department and discharge. Relations between $\mathrm{COHb}$ and MPV were evaluated using Pearson correlation analysis. Significance was set at $p<0.05$. 


\section{RESULTS}

\section{Clinical and Demographic Characteristics}

Eighty-nine patients with $\mathrm{CO}$ poisoning and 20 healthy volunteers were included in the study. No patients died during the study, and all intoxications were accidental. Forty-six (51.7\%) of the 89 patients with CO poisoning were male, and 43 (48.3\%) were female. Ten (50\%) of the 20 healthy volunteers constituting the control group were male, and $10(50 \%)$ were women. There was no statistical significance between the groups in terms of gender distribution ( $p=0.894$ ). The mean age of the patients in the CO poisoning group was $39.3 \pm 16.1$ years, compared to $38.1 \pm 7.4$ in the control group. The difference was not statistically significant $(p=0.747)$. Demographic data for the study group are shown in Table 1.

\section{Basic Results}

$\mathrm{COHb}$ at the time of presentation of patients with $\mathrm{CO}$ poisoning was $22.4 \pm 8.8$ (\%), and MPV levels were $9.26 \pm 0.99$ femtolitre (fL). The mean MPV level in the healthy volunteers constituting the control group was $7.57 \pm 0.51$ (fL). MPV levels at the time of presentation in patients with $\mathrm{CO}$ poisoning were significantly higher than those in the control group $(p<0.001)$. No correlation was determined between $\mathrm{COHb}$ and MPV levels in patients with $\mathrm{CO}$ poisoning $(r=0.142, p=0.186)$. $\mathrm{COHb}$ and MPV levels according to symptoms and findings at the time of presentation in our patients with $\mathrm{CO}$ poisoning are shown in Table 2. Based on our findings, $\mathrm{COHb}$ levels in patients with ischemic-type chest pain among symptoms at presentation were significantly higher than those in patients without chest pain $(p=0.008)$. No significant correlation was determined between other symptoms and findings and $\mathrm{COHb}$ and MPV levels.

\section{Relations Between MPV and Myocardial and Neurological Injury}

Nine patients (10.1\%) were classified as the CO poisoningrelated myocardial injury group. Fifty-four patients (60.7\%) were classified as patients with $\mathrm{CO}$ poisoning-related neurological injury. $\mathrm{COHb}$ and MPV levels measured at the time of presentation and discharge based on CO poisoning-related myocardial or neurological injury based on this classification are shown in Table 3. Receiver-operating characteristic (ROC) curves obtained from ROC analysis performed in order to determine optimal cut-off values for $\mathrm{COHb}$ and MPV levels at the time of presentation in the prediction of myocardial and neurological injury are presented in Figures 1a, 1b, and 2a, 2b. Probable and optimal cut-off values based on these curves are shown in Tables 4 and 5.
Based on these findings, $\mathrm{COHb}$ levels at the time of presentation were higher in subjects with myocardial injury than in those without. However, MPV levels in subjects with a myocardial injury did not differ from levels in those without. Similarly, neither $\mathrm{COHb}$ nor MPV values investigated at the time of presentation emerged as markers of neurological injury.

Table 1. Demographic characteristics of patients with carbon monoxide poisoning

\begin{tabular}{|c|c|}
\hline \multicolumn{2}{|l|}{ Characteristics } \\
\hline \multicolumn{2}{|l|}{ Sex $n,(\%)$} \\
\hline M & $46(51.7)$ \\
\hline $\mathrm{F}$ & $43(48.3)$ \\
\hline Age (mean \pm SD) & $39.3 \pm 16.1$ \\
\hline M & $37.1 \pm 14.2$ \\
\hline $\mathrm{F}$ & $41.7 \pm 17.9$ \\
\hline \multicolumn{2}{|c|}{ Cause of exposure to $\mathrm{CO} n$, (\%) } \\
\hline Stove & $73(82 \%)$ \\
\hline Fire/smoke & $9(10 \%)$ \\
\hline Water heater & $6(7 \%)$ \\
\hline Generator & $1(1 \%)$ \\
\hline \multicolumn{2}{|c|}{ The month of exposure to CO } \\
\hline October & $9(10 \%)$ \\
\hline November & $6(7 \%)$ \\
\hline December & $12(14 \%)$ \\
\hline January & $23(25 \%)$ \\
\hline February & $11(13 \%)$ \\
\hline March & $23(25 \%)$ \\
\hline April & $5(6 \%)$ \\
\hline \multicolumn{2}{|c|}{ Symptoms and findings at the time of presentation $n,(\%)$} \\
\hline Headache & $64(71.9 \%)$ \\
\hline Nausea-vomiting & $55(61.8 \%)$ \\
\hline Dizziness & $47(52.8 \%)$ \\
\hline Lethargy & $47(52.8 \%)$ \\
\hline Clouded consciousness & $13(14.6 \%)$ \\
\hline Palpitation & $11(12.4 \%)$ \\
\hline Blurred vision & $8(9 \%)$ \\
\hline Respiratory difficulty & $7(7.9 \%)$ \\
\hline Chest pain & $7(7.9 \%)$ \\
\hline Troponin-I increase & $7(7.9 \%)$ \\
\hline Loss of consciousness & $4(4.5 \%)$ \\
\hline Ischemic ECG change & $4(4.5 \%)$ \\
\hline Muscle pain & $1(1.1 \%)$ \\
\hline Abdominal pain & $1(1.1 \%)$ \\
\hline
\end{tabular}

CO: Carbon monoxide, MPV: Mean platelet volume, SD: Standard deviation, ECG: Electrocardiography, F: Female, M: Male 
Table 2. Carboxyhemoglobin and mean platelet volume levels at the time of presentation to the emergency service in patients with carbon monoxide poisoning in terms of symptoms and findings

\begin{tabular}{|c|c|c|c|}
\hline & & \multicolumn{2}{|l|}{ Parameter } \\
\hline & & $\begin{array}{l}\text { COHb \% } \\
(\text { Mean } \pm \text { SD) }\end{array}$ & $\begin{array}{l}\text { MPV fL } \\
(\text { Mean } \pm S D)\end{array}$ \\
\hline \multirow[t]{3}{*}{ Headache $(n=64)$} & + & $22.68 \pm 9.27$ & $9.33 \pm 1.01$ \\
\hline & - & $21.86 \pm 7.70$ & $9.08 \pm 0.93$ \\
\hline & $p$ values & 0.696 & 0.292 \\
\hline \multirow[t]{3}{*}{ Nausea-vomiting $(n=55)$} & + & $22.42 \pm 8.60$ & $9.30 \pm 0.97$ \\
\hline & - & $22.50 \pm 9.30$ & $9.19 \pm 1.04$ \\
\hline & $\mathrm{p}$ value & 0.968 & 0.626 \\
\hline \multirow[t]{3}{*}{ Dizziness ( $n=47)$} & + & $22.70 \pm 9.18$ & $9.05 \pm 1.09$ \\
\hline & - & $22.18 \pm 8.51$ & $9.49 \pm 0.82$ \\
\hline & $p$ values & 0.785 & 0.041 \\
\hline \multirow[t]{3}{*}{ Lethargy $(n=47)$} & + & $24.12 \pm 8.64$ & $9.39 \pm 0.95$ \\
\hline & - & $20.59 \pm 8.75$ & $9.11 \pm 1.03$ \\
\hline & $\mathrm{p}$ value & 0.059 & 0.185 \\
\hline \multirow{3}{*}{$\begin{array}{l}\text { Clouded consciousness } \\
(n=13)\end{array}$} & + & $24.95 \pm 10.35$ & $9.46 \pm 1.05$ \\
\hline & - & $22.08 \pm 8.59$ & $9.21 \pm 0.98$ \\
\hline & $p$ value & 0.283 & 0.398 \\
\hline \multirow[t]{3}{*}{ Palpitation $(n=11)$} & + & $25.85 \pm 10.93$ & $9.70 \pm 0.85$ \\
\hline & - & $21.97 \pm 8.46$ & $9.20 \pm 1.00$ \\
\hline & $p$ value & 0.174 & 0.113 \\
\hline \multirow[t]{3}{*}{ Blurred vision $(n=8)$} & + & $24.15 \pm 11.2$ & $9.52 \pm 1.05$ \\
\hline & - & $22.34 \pm 8.66$ & $9.22 \pm 0.99$ \\
\hline & $p$ value & 0.585 & 0.420 \\
\hline \multirow{3}{*}{$\begin{array}{l}\text { Respiratory difficulty } \\
(n=7)\end{array}$} & + & $22.71 \pm 11.31$ & $9.55 \pm 0.77$ \\
\hline & - & $22.43 \pm 8.66$ & $9.23 \pm 1.01$ \\
\hline & $p$ value & 0.937 & 0.419 \\
\hline \multirow[t]{3}{*}{ Chest pain $(n=7)$} & + & $30.84 \pm 11.69$ & $9.80 \pm 0.17$ \\
\hline & - & $21.74 \pm 8.24$ & $9.21 \pm 0.97$ \\
\hline & $p$ values & 0.008 & 0.138 \\
\hline \multirow{3}{*}{$\begin{array}{l}\text { Troponin-I increase } \\
(\mathrm{n}=7)\end{array}$} & + & $25.02 \pm 11.79$ & $9.71 \pm 0.89$ \\
\hline & - & $22.23 \pm 8.58$ & $9.22 \pm 0.99$ \\
\hline & $p$ value & 0.425 & 0.213 \\
\hline \multirow{3}{*}{$\begin{array}{l}\text { Loss of consciousness } \\
(n=4)\end{array}$} & + & $27.40 \pm 14.83$ & $9.75 \pm 1.25$ \\
\hline & - & $22.27 \pm 8.55$ & $9.22 \pm 0.98$ \\
\hline & $p$ value & 0.261 & 0.309 \\
\hline \multirow{3}{*}{$\begin{array}{l}\text { Ischemic ECG change } \\
(\mathrm{n}=4)\end{array}$} & + & $27.52 \pm 14.56$ & $9.80 \pm 1.33$ \\
\hline & - & $22.22 \pm 8.52$ & $9.23 \pm 0.98$ \\
\hline & $p$ value & 0.242 & 0.272 \\
\hline \multirow[t]{3}{*}{ Muscle pain $(n=1)$} & + & $22.90 \pm 0$ & $9.10 \pm 0$ \\
\hline & - & $22.37 \pm 8.84$ & $9.26 \pm 1.00$ \\
\hline & $p$ value & 0.400 & 0.870 \\
\hline \multirow[t]{3}{*}{ Abdominal pain $(n=1)$} & + & $14.70 \pm 0$ & $9.70 \pm 0$ \\
\hline & - & $22.54 \pm 8.83$ & $9.25 \pm 1.00$ \\
\hline & $p$ value & 0.380 & 0.661 \\
\hline \multicolumn{4}{|c|}{$\begin{array}{l}\text { MPV: Mean platelet volume, } \mathrm{COHb} \text { : Carboxyhemoglobin, ECG: Electrocardiography } \\
\text { SD: Standard deviation, fL: Femtolitre, } p<0.05\end{array}$} \\
\hline
\end{tabular}

\section{The Effect of Normobaric or Hyperbaric Oxygen Therapy on MPV Levels}

Eighty (89.9\%) of our patients received NBO therapy, and 9 (10.1\%) received HBO therapy. Pre-treatment $\mathrm{COHb}$ levels of patients presenting to our emergency department with $\mathrm{CO}$ poisoning

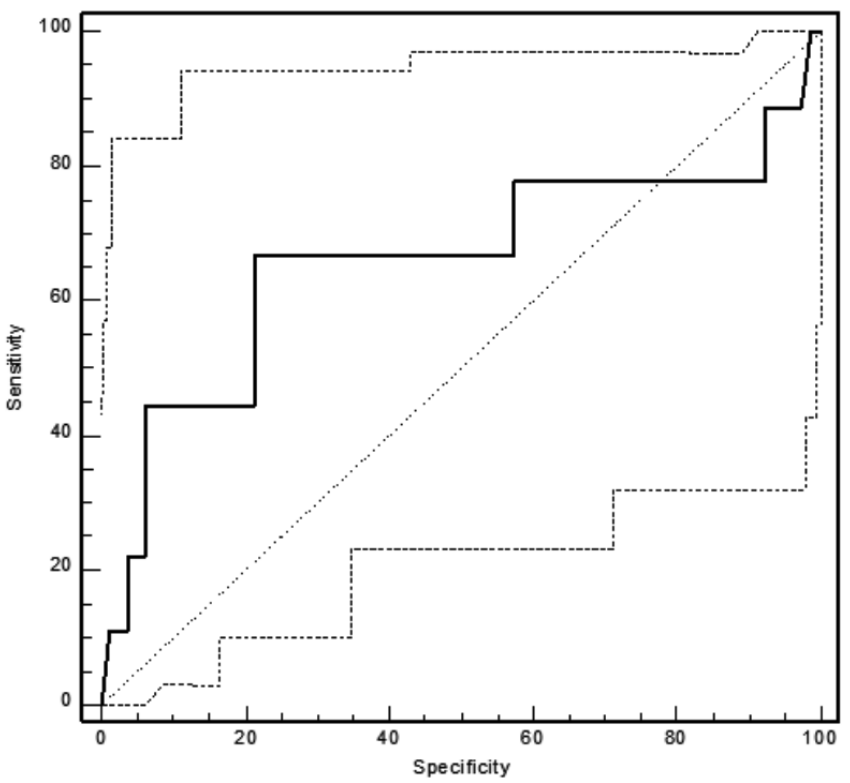

Figure 1a. ROC curves obtained at ROC analysis performed to determine the optimal cut-off of $\mathrm{COHb}$ levels for the development of $\mathrm{CO}$ poisoningrelated myocardial injury

ROC: Receiver-operating characteristic, $\mathrm{COHb}$ : Carboxyhemoglobin, $\mathrm{CO}$ : Carbon monoxide

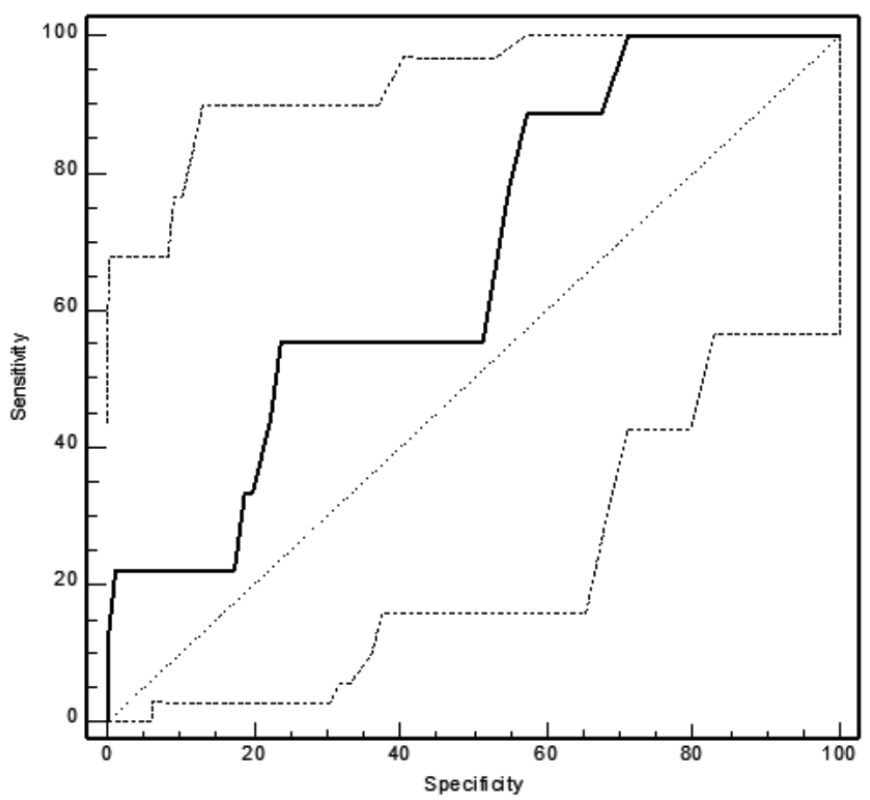

Figure 1b. ROC curves obtained at ROC analysis performed to determine the optimal cut-off of MPV levels for the development of CO poisoningrelated myocardial injury

ROC: Receiver-operating characteristic, MPV: Mean platelet volume, CO: Carbon monoxide 
were $22.4 \pm 8.8(\%)$, decreasing to $2.71 \pm 1.33$ (\%) after therapy. Pre-treatment MPV levels were 9.26 $\pm 0.99(\mathrm{fL})$, decreasing to $8.86 \pm 0.95(\mathrm{fL})$ after treatment. These decreases in $\mathrm{COHb}$ and MPV levels after NBO or HBO were significant $(p<0.001)$.

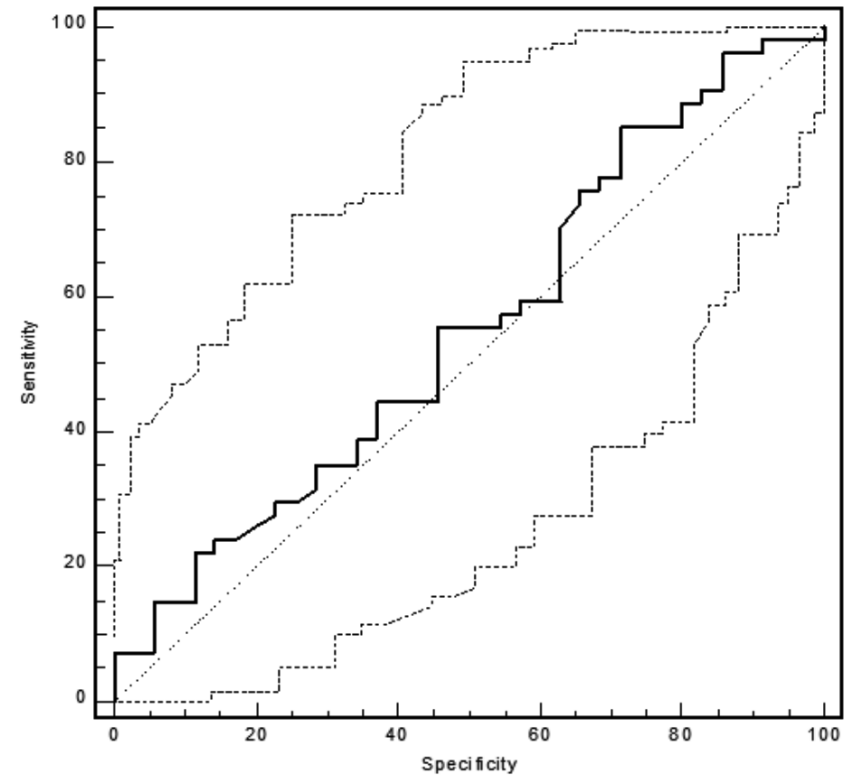

Figure 2a. ROC curves obtained at ROC analysis performed to determine the optimal cut-off of $\mathrm{COHb}$ levels for the development of $\mathrm{CO}$ poisoningrelated neurological injury

ROC: Receiver-operating characteristic, $\mathrm{COHb}$ : Carboxyhemoglobin, $\mathrm{CO}$ : Carbon monoxide

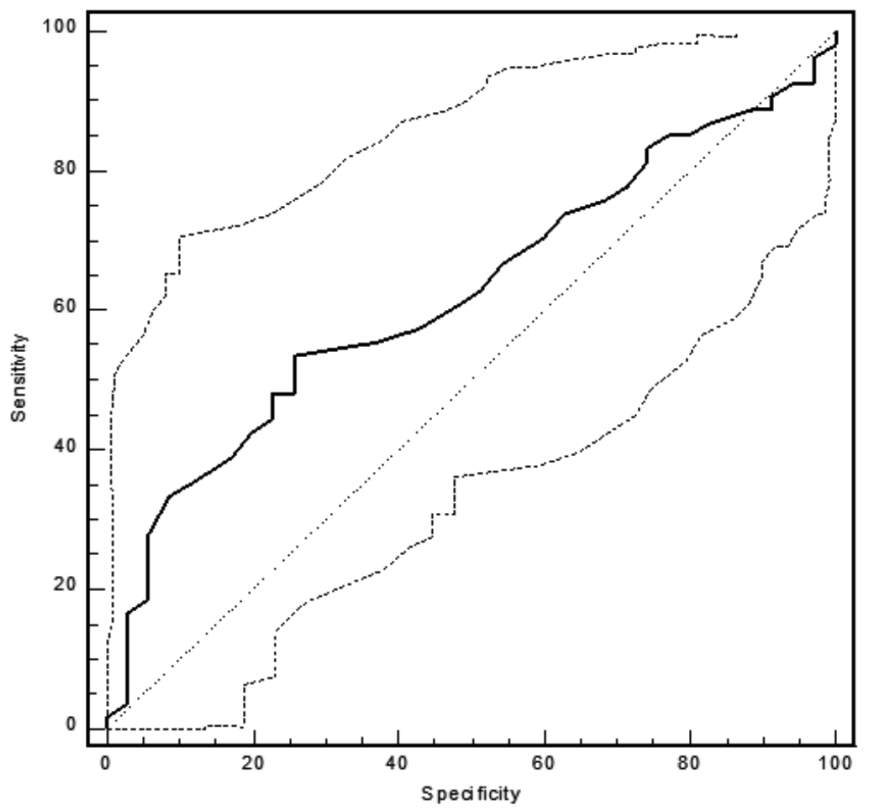

Figure $\mathbf{2 b}$. ROC curves obtained at ROC analysis performed to determine the optimal cut-off of MPV levels for the development of CO poisoningrelated neurological injury

ROC: Receiver-operating characteristic, MPV: Mean platelet volume, CO: Carbon monoxide

\section{DISCUSSION}

This study was planned on the hypothesis of a potential relation between MPV levels and clinical symptoms in patients with CO poisoning. We investigated the relationship between MPV levels and the development of myocardial or neurological injury. Although significantly higher MPV levels were determined in patients with CO poisoning compared to the healthy controls, that elevation was not associated with clinical symptoms and findings. It does not appear possible for high MPV levels in patients with CO poisoning to be used as a marker or myocardial or neurological injury.

Serum $\mathrm{COHb}$ level is still the most crucial test in the diagnosis of CO poisoning. However, several studies in the literature show no correlation between $\mathrm{COHb}$ elevation and clinical severity (15). Initially investigated $\mathrm{COHb}$ levels are not correlated with symptoms, the severity of intoxication, or late neurological sequelae that may develop. This may be attributed to the time lost until arrival at the emergency department or to a rapid decrease in $\mathrm{COHb}$ levels with oxygen therapy administered before arrival at the hospital so that $\mathrm{COHb}$ levels measured on arrival at the emergency department are too low to be associated with the clinical condition $(15,16)$. Although high $\mathrm{COHb}$ levels are essential in the diagnosis of the disease, predicting the clinical course based on this parameter will not be particularly reliable. In this study, we investigated the association between clinical intoxication and MPV shown to rise in hypoxic conditions in addition to $\mathrm{COHb}$ levels. $\mathrm{COHb}$ and MPV levels in the determination of myocardial and neurological injury in CO poisoning were evaluated based on symptoms at the time of presentation and clinical markers during observation. Based on our findings, only $\mathrm{COHb}$ levels of patients with ischemic-

Table 3. Carboxyhemoglobin and mean platelet volume levels at the time of presentation to the emergency department in terms of carbon monoxide poisoning-related myocardial and neurological injury and carboxyhemoglobin and mean platelet volume levels at the time of discharge

\begin{tabular}{|l|l|l|l|}
\hline \multicolumn{2}{|c|}{} & \multicolumn{2}{|l|}{ Presentation } \\
\cline { 2 - 4 } \multicolumn{2}{|c|}{} & $\begin{array}{l}\text { COHb \% } \\
\text { (Mean } \pm \text { SD) }\end{array}$ & $\begin{array}{l}\text { MPV fL } \\
\text { (Mean } \pm \text { SD) }\end{array}$ \\
\hline $\begin{array}{l}\text { Myocardial injury } \\
(\mathbf{n = 9})\end{array}$ & + & $28.28 \pm 12.21$ & $9.19 \pm 0.97$ \\
\cline { 2 - 4 } & - & $21.80 \pm 8.20$ & $9.83 \pm 1.02$ \\
\cline { 2 - 4 } & p value & $\mathbf{0 . 0 3 6}$ & 0.070 \\
\hline $\begin{array}{l}\text { Neurological injury } \\
\text { (n=54) }\end{array}$ & + & $23.14 \pm 9.08$ & $9.11 \pm 1.04$ \\
\cline { 2 - 4 } & - & $21.40 \pm 8.42$ & $9.49 \pm 0.87$ \\
\cline { 2 - 4 } & p value & 0.365 & 0.078 \\
\hline
\end{tabular}

MPV: Mean platelet volume, $\mathrm{COHb}$ : Carboxyhemoglobin, SD: Standard deviation, $p<0.05$ 
type chest pain symptoms at the time of presentation and evaluated as having myocardial injury were significantly higher than those of subjects with no such symptoms. No significant correlation was observed between $\mathrm{COHb}$ and MPV levels and other symptoms and findings.

MPV is a marker of platelet function and activation. MPV has been shown to increase in association with an increase in young platelets in the circulation in the presence of a stress factor stimulating platelet production (17). In our study, MPV levels studied at the time of presentation to the emergency department in cases of $\mathrm{CO}$ poisoning were significantly higher compared to the MPV levels of healthy individuals. Karabacak et al. (12) also reported significantly higher MPV values in patients with CO poisoning compared to a healthy control group. However, and similarly to Karabacak et al. (12) study, the MPV levels in our study being higher than those in healthy individuals confirming the idea that platelet activation is an essential component of the pathogenesis of $\mathrm{CO}$ poisoning. The factor most probably leading to platelet activation in CO poisoning is thought to derive from various mechanisms triggering hypoxia. CO impairs the electron transport chain by binding to cytochrome c oxidase, increases the level of nitric oxide released from thrombocytes, and increases the production of free oxygen radicals (18). Increased free oxygen radicals lead to changes in platelet aggregation and adhesion and blood circulation (12). This entire process can be

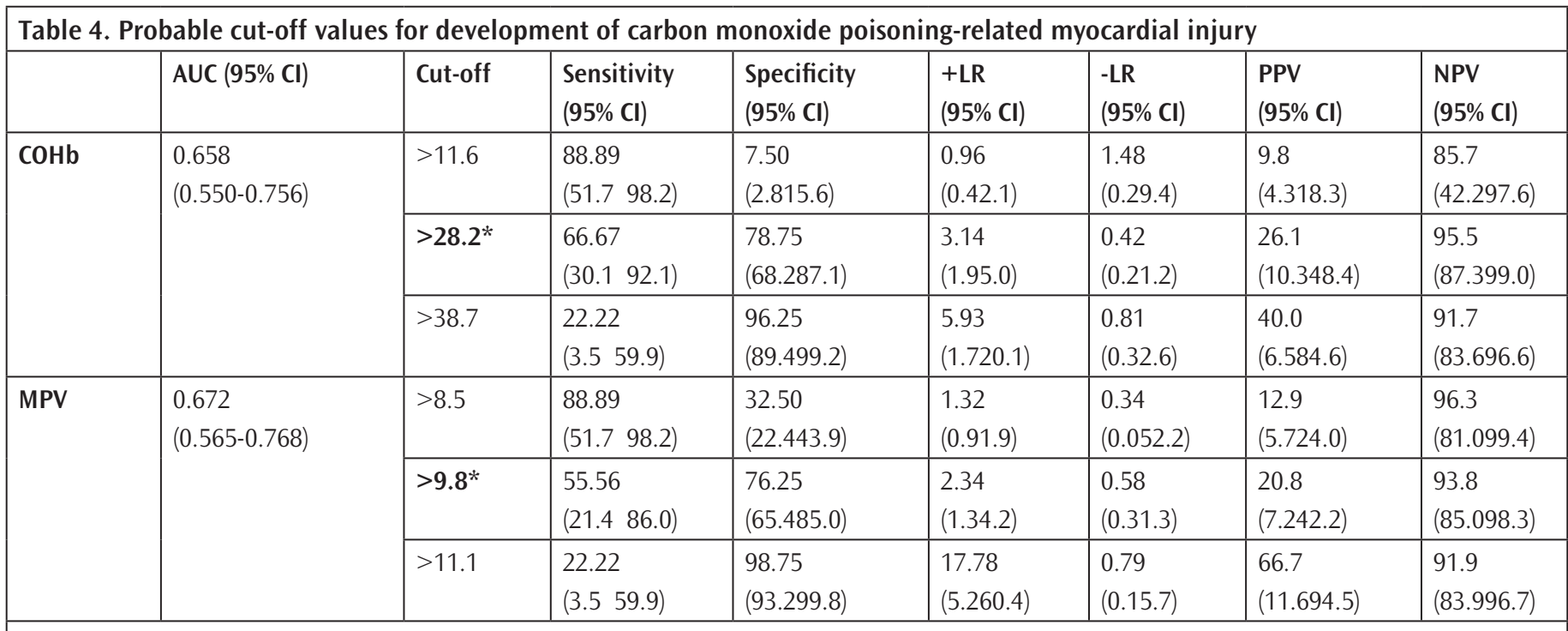

MPV: Mean platelet volume, COHb: Carboxyhemoglobin, +LR: Positive likelihood ratio, -LR: Negative likelihood ratio, PPV: Positive predictive value, NPV: Negative predictive value, AUC: Area under curve, Cl: Confidence interval, *: Optimal cut-off values

\begin{tabular}{|c|c|c|c|c|c|c|c|c|}
\hline & AUC (95\% Cl) & Cut-off & $\begin{array}{l}\text { Sensitivity } \\
(95 \% \mathrm{CI})\end{array}$ & $\begin{array}{l}\text { Specificity } \\
(95 \% \mathrm{CI})\end{array}$ & $\begin{array}{l}+\mathrm{LR} \\
(95 \% \mathrm{Cl})\end{array}$ & $\begin{array}{l}- \text {-LR } \\
(95 \% \mathrm{Cl})\end{array}$ & $\begin{array}{l}\text { PPV } \\
(95 \% \mathrm{Cl})\end{array}$ & $\begin{array}{l}\text { NPV } \\
(95 \% \mathrm{Cl})\end{array}$ \\
\hline $\mathrm{COHb}$ & $\begin{array}{l}0.553 \\
(0.444-0.659)\end{array}$ & $>13.9 *$ & $\begin{array}{l}85.19 \\
(72.993 .4)\end{array}$ & $\begin{array}{l}28.57 \\
(14.746 .3)\end{array}$ & $\begin{array}{l}1.19 \\
(0.72 .0)\end{array}$ & $\begin{array}{l}0.52 \\
(0.31 .0)\end{array}$ & $\begin{array}{l}64.8 \\
(52.575 .8)\end{array}$ & $\begin{array}{l}55.6 \\
(30.878 .4)\end{array}$ \\
\hline \multirow[t]{2}{*}{ MPV } & \multirow[t]{2}{*}{$\begin{array}{l}0.625 \\
(0.516-.725)\end{array}$} & $\leq 8$ & $\begin{array}{l}16.67 \\
(7.929 .3)\end{array}$ & $\begin{array}{l}97.14 \\
(85.099 .5)\end{array}$ & $\begin{array}{l}5.83 \\
(3.210 .6)\end{array}$ & $\begin{array}{l}0.86 \\
(0.15 .9)\end{array}$ & $\begin{array}{l}90.0 \\
(55.598 .3)\end{array}$ & $\begin{array}{l}43.0 \\
(31.954 .7)\end{array}$ \\
\hline & & $\leq 9 *$ & $\begin{array}{l}53.70 \\
(39.667 .4)\end{array}$ & $\begin{array}{l}74.29 \\
(56.787 .5)\end{array}$ & $\begin{array}{l}2.09 \\
(1.52 .9)\end{array}$ & $\begin{array}{l}0.62 \\
(0.31 .2)\end{array}$ & $\begin{array}{l}76.3 \\
(59.888 .5)\end{array}$ & $\begin{array}{l}51.0 \\
(36.665 .2)\end{array}$ \\
\hline
\end{tabular}


regarded as the mechanism causing an increase in MPV in CO poisoning. Interleukin- 6 has been shown to cause an increase in platelet volume during thrombopoiesis in bone marrow in various other hypoxic conditions other than CO poisoning (1921). High MPV values are associated with cardiovascular and cerebrovascular pathologies giving rise to significant morbidity and mortality (22-24). Platelets may also play a significant role in the development of cardiovascular and cerebrovascular events in subsequent periods in patients with CO poisoning. In our study, however, we determined no significant elevation in MPV levels in the myocardial injury group established based on the criteria of ischemic chest pain, ischemic ECG changes, or increased troponin levels. Similarly, no significant difference was observed in MPV levels between patients with CO poisoning and suspected neurological injury compared to those with no such injury. However, the fact that NBO or HBO caused a significant decrease in MPV levels, as well as $\mathrm{COHb}$, suggests that MPV levels may be useful in evaluating the effectiveness of treatment. If further, wider-ranging studies support this, then MPV values may be used as a marker for guiding treatment in patients with $\mathrm{CO}$ poisoning, and patients with MPV elevation may require closer monitoring or more aggressive treatment.

A few studies have shown that MPV levels decrease with the correction of hypoxia. In a study of patients with obstructive sleep apnea syndrome (OSAS), Varol et al. (25) assessed the effectiveness of continuous positive airway pressure (CPAP) therapy on MPV. They reported that MPV values were significantly higher in patients with severe OSAS compared to the control group and that 6-month CPAP therapy led to a significant decrease in MPV values in patients with severe disease (25). Similarly, in our study, oxygen therapy administered to cases of CO poisoning significantly reduced MPV.

The basis of the treatment in CO poisoning is the elimination of $\mathrm{CO}$ and the minimization of injury, together with the reversal of cellular metabolic dysfunction. The most critical step in the treatment of CO poisoning is the administration of $100 \%$ oxygen. Patients with a high suspicion of $\mathrm{CO}$ poisoning must be started on NBO therapy without waiting for the $\mathrm{COHb}$ results. HBO therapy is required for patients with confusion, altered consciousness, a history of loss of consciousness (presyncope or syncope), convulsion, coma, focal neurological deficit or findings of acute myocardial ischemia, pregnant subjects with $\mathrm{COHb}$ levels above $15 \%$, or with symptoms (headache or neurological symptoms) persisting despite 4-6 h 100\% NBO therapy (26). The HBO option is not available in most centers. Treatment is, therefore, usually restricted to NBO. Although the option of $\mathrm{HBO}$ is available in the center in which the study was performed, very few patients have received this due to the lack of an underwater and hyperbaric physician able to provide the service. Problems regarding the means for providing HBO or inaccessibility of a physician capable of performing it are a significant problem frequently encountered in the management of patients with CO poisoning.

When CO binds to myoglobin in heart muscle, it impairs oxygen transport in the mitochondria and causes myocardial dysfunction. Myocardial ischemia results from an imbalance between blood supply and oxygen requirements in the myocardium. One study showed that CO poisoning also elevated cardiac markers in patients with healthy cardiac arteries. That study reported high creatine kinase - myocardial band and Tn-I levels in 30\% of patients without obstructive lesions (27). Based on our results, only $\mathrm{COHb}$ levels investigated at the time of presentation are higher in patients with myocardial injury compared to patients without myocardial injury and may represent a marker capable of use in predicting myocardial injury. However, MPV levels investigated at the time of presentation do not vary between patients with or without myocardial injury. Since rising MPV in patients with CO poisoning plays a vital role in the development and progression of intracoronary thrombus, MPV may be a risk factor for myocardial infarction in the chronic period. MPV may, therefore, be a marker capable of use in predicting myocardial injury that occurs in later stages in patients with $\mathrm{CO}$ intoxication. Wider-ranging studies are now needed to determine this.

We determined no significant elevation in either $\mathrm{COHb}$ or MPV levels at the time of presentation in patients we classified as having CO poisoning-related neurological injury. The decrease in $\mathrm{COHb}$ and MPV levels and improvement in some symptoms may be due, as already described, to the time lost before patients' arrival at the emergency department or to oxygen therapy administered by the 112 emergency service.

\section{Limitations}

This study has several limitations. First, our study population was small, and the number of cases with severe CO poisoning was very low. Therefore, in post hoc power analysis, the power of our study was determined as $62 \%$. Our findings may be affected by the low number of severe $\mathrm{CO}$ poisoning patients and the low number of CO poisoning patients, especially cardiac damage. The difference between MPV levels in patients with neurologic or myocardial damage and non-CO poisoning may have caused this situation to be meaningless. Second, the oxygen therapy administered by the 112 emergency service during transportation may have caused changes in $\mathrm{COHb}, \mathrm{MPV}$, and symptoms and thus have prevented us from obtaining reliable findings. Although the center where 
this study was performed does have the equipment with which to provide HBO, very few patients receive it due to the lack of an underwater and hyperbaric physician therapeutic option.

\section{CONCLUSIONS}

Based on our study findings, MPV in CO poisoning increases significantly compared to that in healthy individuals and decreases after oxygen therapy. However, this elevation does not appear to be a parameter correlated with which symptoms or findings will be seen in which patient, nor to be an effective predictor of myocardial or neurological injury.

\section{Ethics}

Ethics Committee Approval: Kanuni Training and Research Hospital (No: 2014/13)

Informed Consent: Informed consent was given from all patients volunteering to participate, or from relatives if patients were unable to express consent

Peer-review: Externally and internally peer-reviewed

\section{Authorship Contributions}

Surgical and Medical Practices: A.A.T., G.A., S.A., Ö.T., Concept: S.T., Design: S..A., A.A.T., Data Collection or Processing: A.A.T., G.A., Analysis or Interpretation: S.T., A.S., Literature Search: A.A.T., G.A., Writing: A.A.T., A.A.

Conflict of Interest: The authors state no conflict of interest.

Financial Disclosure: There is no source of funds or financial support in the study.

\section{REFERENCES}

1. Omaye ST. Metabolic modulation of carbon monoxide toxicity. Toxicology 2002;180:139-50.

2. Y Incekaya, H Feyizi, S Bayraktar, Ali I, Topuz C, Karacalar S, ve ark. Karbonmonoksit Zehirlenmesi ve Hiperbarik Oksijen Tedavisi. Okmeydanı Tıp Dergisi 2017;33:114-8.

3. Sever H, Ikizceli I, Avsarogulları L, Sozuer M, Ozkan S, Yurumez Y, et al. Carbonmonoxide poisoning among patients presenting with nonspesific symptoms to the emergency department. Turk J Emerg Med 2005;5:1821.

4. Piantadosi CA. Carbon monoxide poisoning. N Engl J Med 2002;347:1054-5.

5. Lemke T, Wang R. Emergency department observation for toxicologic exposures. Emerg Med Clin North Am 2001;19:155-67, viii.

6. Hardy KR, Thom SR. Pathophysiology and treatment of carbon monoxide poisoning. J Toxicol Clin Toxicol 1994;32:613-29.

7. Yurtseven S, Arslan A, Eryigit U, Gunaydin M, Tatli O, Ozsahin F, et al. Analysis of patients presenting to the emergency department with carbon monoxide intoxication. Turk J Emerg Med 2016;15:159-62.
8. Gazi DA, Helvacı ŞA, Ataş UY, Erkuş E. Akut Koroner Sendromda Aneminin Rolü. Okmeydanı Tıp Dergisi 2014;30:21-5.

9. Kao LW, Nanagas KA. Carbon monoxide poisoning. Emergency medicine clinics of North America 2004;22:985-1018.

10. Gorman D, Drewry A, Huang YL, Sames C. The clinical toxicology of carbon monoxide. Toxicology 2003;187:25-38.

11. Smyth SS, McEver RP, Weyrich AS, Morrell CN, Hoffman MR, Arepally GM, et al. Platelet Colloquium Participants. Platelet functions beyond hemostasis. J Thromb Haemost 2009;7:1759-66.

12. Karabacak M, Varol E, Turkdogan KA, Duman A, Akpinar O, Karabacak P. Mean platelet volume in patients with carbon monoxide poisoning. Angiology 2014;65:252-6.

13. Kapsoritakis AN, Koukourakis MI, Sfiridaki A, Potamianos SP, Kosmadaki MG, Koutroubakis IE, et al. Mean platelet volume: a useful marker of inflammatory bowel disease activity. Am J Gastroenterol 2001;96:77681.

14. Ulu S, Bucak A, Koken R, Kuzu S, Aycicek A. Mean Platelet Volume as a Potential Marker for Predicting Hypoxia in Children with Adenotonsillar Hypertrophy. Van Tıp Dergisi 2015;22:10-3.

15. Hampson NB, Hauff NM. Carboxyhemoglobin levels in carbon monoxide poisoning: do they correlate with the clinical picture? Am J Emerg Med 2008;26:665-9.

16. Keles A, Demircan A, Kurtoglu G. Carbon monoxide poisoning: how many patients do we miss? Eur J Emerg Med 2008;15:154-7.

17. Park Y, Schoene N, Harris W. Mean platelet volume as an indicator of platelet activation: methodological issues. Platelets 2002;13:301-6.

18. Thom SR, Bhopale VM, Han S, Clark JM, Hardy KR. Intravscular neutrophil activation due to carbon monoxide poisoning. Am J Respir Crit Care Med 2006;174:1239-48.

19. Sagit M, Korkmaz F, Kavugudurmaz M, Somdas MA. Impact of septoplasty on mean platelet volume levels in patients with marked nasal septal deviation. J Craniofac Surg 2012;23:974-6.

20. Nena E, Papanas N, Steiropoulos P, Zikidou P, Zarogoulidis P, Pita E, et al. Mean Platelet Volume and Platelet Distribution Width in nondiabetic subjects with obstructive sleep apnoea syndrome: new indices of severity? Platelets 2012;23:447-54.

21. Brown AS, Hong Y, de Belder A, Beacon H, Beeso J, Sherwood R, et al. Megakaryocyte ploidy and platelet changes in human diabetes and atherosclerosis. Arterioscler Thromb Vasc Biol 1997;17:802-7.

22. Senaran H, Ileri M, Altinbas A, Kosar A, Yetkin E, Oztürk M, et al. Thrombopoietin and mean platelet volume in coronary artery disease. Clin Cardiol 2001;24:405-8.

23. Bath P, Algert C, Chapman N, Neal B; PROGRESS Collaborative Group Association of mean platelet volume with risk of stroke among 3134 individuals with history of cerebrovascular disease. Stroke 2004;35:622-6.

24. Smith NM, Pathansali R, Bath PM. Platelets and stroke. Vasc Med 1999;4:165-72.

25. Varol E, Ozturk O, Yucel H, Gonca T, Has M, Dogan A, et al. The effects of continuous positive airway pressure therapy on mean platelet volume in patients with obstructive sleep apnea. Platelets 2011;22:552-6.

26. Bentur Y. Hyperbaric oxygen for carbon monoxide poisoning. Toxicol Rev. 2005;24:153-4; discussion 159-60.

27. Kalay N, Ozdogru I, Cetinkaya Y, Eryol NK, Dogan A, Gul I, et al. Cardiovascular effects of carbon monoxide poisoning. Am J Cardiol 2007;99:322-4. 